\title{
Cognitive timescales in highly skilled physical actions learned through practice: a 20-year participant observation analysis of recreational surfing.
}

\begin{abstract}
This analysis aims to identify the specialist cognitive skills used in recreational surfing, and the time scales at which they operate. It employs participant observation from 2000 hours' surfing over 20 years, including 5000 waves ridden and 500,000 waves observed. It shows that cognitive components of surfing skills operate at timescales from days down to subseconds. Cognitive skills are learned through repeated observation and practice, at all timescales. Longer timescales allow for reconsideration of individual action decisions; shorter timescales do not. Practice improves the ability to anticipate outcomes, even at very short timescales. At sub-second timescales, skilled practitioners achieve self-perceived subjective time dilation, which permits awareness of attention, actions, and decisions even during high-speed, physically skilled and practiced manoeuvres. That is, features of brain operation generally associated with "slow" cognition, persist even at short timescales generally associated with "fast" autonomic physical motor control. Qualitative analysis of the psychology of surfing and similar adventurous outdoor nature sports can thus make a significant contribution to broader understanding of human brain function and evolution.
\end{abstract}

Keywords: sport; practice; attention; decision; action; performance

\section{Introduction}

Athletic competence at adventurous outdoor nature sports requires fitness, activity-specific physical skills, and activity-specific cognitive capabilities (Ericsson et al., 2006; Mann et al., 2007; Chan et al., 2011; Montero, 2016; Araújo et al., 2017; Bilalić, 2017; Feletti et al., 2017; Feletti \& Brymer, 2018; Gombeski et al., 2017; Hallandvik et al., 2017; Immonen et al., 2017; Jamal et al., 2019; Toner \& Moran, 2017). In particular, these skills are required for surfing and related sports (Mendez-Villanueva \& Bishop, 2005; Mendez-Villanueva et al., 2005; Chapman et al., 2008; Brymer \& Oades, 2009; Furley and Dörr, 2016; Andrianopoulos \& Vogiatzis, 2017; Portugal et al., 2017; Taylor \& Elia, 2017; Wheaton, 2017). To date, however, there has been only one analysis of cognitive skills in surfing. Using a video-based experiment, Furley and Dörr (2016) showed that expert surfers, but not novices, select waves that can provide maximum scoreable points during competition. This, however, is only one of many cognitive components in surfing expertise.

This study argues that surfing requires far more complex cognitive capabilities than wave selection alone. These cognitive components can be distinguished on the basis of timescale. Skills are outlined that operate at timescales of days, hours, minutes, seconds, or tenths or hundredths of a second. Furley and Dörr (2016) argued that cognition is an under-researched component of surf skills. This contribution concurs, and also argues much more broadly, that surfing and similar sports can provide an analytic tool or medium to examine a particular subset of brain operations. That subset consists of connections between thought and action at timescales where conscious thought is needed to initiate action, but where there is no time to change one's mind. That is, these actions involve highly focussed consideration, but with no time for reflection or reconsideration. 
This is currently a key area of psychological and neurological research. A number of sports have been studied: pistol and air-pistol shooting (Cheng et al., 2017; Di Fronso et al., 2016), fencing (Allerdissen et al., 2017), tennis (Denis et al., 2017; Mallek et al., 2017), and volleyball and basketball (Chiu et al, 2016; Kraeutner et al., 2018). A wide range of neurophysiological techniques have been adopted in this research (Karlinsky et al., 2017; Kraeutner et al., 2018). The effect of training on structural microconnectivity of brain grey matter (Draganski et al., 2004), white matter (Kahn et al., 2017) and neural nodes (Telesford et al., 2017) has also been tested. Critical current concepts include: motor imagery and mental rehearsal (Kraeutner et al., 2018); visuomotor skills (Mallek et al., 2017) and their counterpart, action-skilled observation (Karlinsky et al., 2017); action anticipation (Smith, 2016; Denis et al., 2017; Loffing \& Cañal-Bruland, 2017); and cortical sensorimotor oscillations (Di Fronso et al., 2016; Cheng et al., 2017).

Outdoor sports such as surfing and kiteboarding, skiing and snowboarding, whitewater rafting and kayaking, and climbing and mountaineering, have received less attention. There are at least three reasons for this. First, it is more difficult to equip practitioners with neurological monitoring equipment either in the water, or in remote areas. Second, relatively fewer psychology researchers are familiar with activities such as surfing or whitewater kayaking, so it is more difficult for them to identify and conduct potential experimental tests.

Third, where sports involve shots, strokes, or blows, these provide experimental endpoints, with monitoring focussed on the moments leading up to that action. In shooting, for example, the process of aiming ends with the shot. Adventurous outdoor nature sports, in contrast, typically do not halt at crux moves, but continue: the interplay between thought and action extends over longer periods. Actions such as a surfer paddling onto a wave, or a kayaker paddling through whitewater rapids on a river, do not have a defined endpoint. This provides a different set of brain conditions, likely to involve a different pattern of brain operations, and potentially providing different insights into brain function.

Neurological, biochemical and physiological approaches are not the only ways to analyse brain operations. Psychology also includes participant observation, where practitioner researchers study the thoughts and actions of participants, including themselves, through direct observation during actual practice of the activity concerned. Participant observation is a very widely adopted approach, with the original methodological book by Spradley (1980) now cited several thousand times. This approach is equally accessible for researchers analysing activities in water or remote areas, where neurophysiological equipment cannot easily be deployed. It is therefore the method adopted here.

Surfing has been studied extensively from social, cultural, and phenomenological perspectives (Martin and Assenov, 2012; Buckley et al., 2017). In particular, like many adventure sports (Cater and Cloke, 2007), it has been analysed as embodiment (Ford and Brown, 2005). This is a phenomenological approach that links perception, proprioception and action, from the perspective of the participant. It is one offshoot of the phenomenological philosophy of Merleau-Ponty (1945), parallel to the concept of flow (Ford, 2016), also phenomenological. Here, in contrast, I adopt a cognitive psychology approach, distinguishing conscious thought from autonomous action. This is a positivist approach, treating body movements as consequences of sensations, nervous control, and physical actions. Cognitive psychology approaches have been used to analyse performance in many sports, as above; but apart from Furley \& Dorr (2016), not previously in surfing. 
As with most types of outdoor recreation, surfing requires multiple skill sets. 1. Physical fitness. One needs strength and stamina to paddle out. 2. Technical skill. One must be able to ride a surfboard. This skill varies from beginners who can barely stand on a slow small wave, to professionals who can surf large, fast, powerful and dangerous waves. 3. Cognitive skills. To catch a wave, one must get to the right place at the right time, with right of way over other surfers. Surfing requires deliberate attention and decisions. 4. Emotional skills. Surfers must remain calm and collected, not angry or fearful, despite difficulties or danger. For example, waves may break repeatedly on one's head. One may suffer severe wipe-outs. Other surfers may steal one's waves, or get in one's way, or slash close past one, or fall off in front of one. 5. Social skills. One needs to assess attitudes, skills, and expectations of other surfers. They may be competent or incompetent, polite or rude, friendly or aggressive. For safety, one must adjust one's own surfing behaviour accordingly.

\section{Methods}

My focus here is only on cognitive skills. Evidence is derived from participant observation of surfing over two decades. Participant observation can include communication with other participants, a form of ethnography; and observations of one's own actions and psychological states, sometimes referred to as experimental analytical autoethnography (Buckley, 2016a). These approaches have been deployed widely in recent years (Anderson, 2006; Anderson \& Austin, 2012; Buckley, 2015, 2016a,b, 2017; Chang, 2016; Jones et al., 2016; Pace, 2016; Scheidt, 2016; Stahlke Wall, 2016). In outdoor recreation, these approaches provide the ability to analyse a range of otherwise intractable considerations. These include: circumstances with real risk of death; indescribable or "ineffable" emotions; perceived changes in the passage of time; short-term sequences of linked emotions; and effects of ageing on all of these (Morin et al., 2015; Buckley, 2016a, 2018a,b,c,d).

Participant observations, including self-observation, are particularly valuable in analysing extreme or adventurous nature sports, because they can provide fine detail of events and emotions (Brymer \& Schweitzer, 2017b; Buckley, 2015). This occurs through "slow-time" experience (Arstila, 2012; Buckley, 2014; Wittman, 2011) and "critical incident" recall (Bradburn et al., 1987; Brown \& Kulik, 1977; Flanagan, 1954; Loftus, 2017; Winkler, 2017). Such recall persists despite the passage of time (Gardner et al., 2015). Activities analysed in previous studies include skiing, snowboarding, kiteboarding, hang-gliding, sailboarding, surfing, white-water kayaking, diving, and encounters with potentially dangerous animals.

Standard ethnographic approaches, involving deliberate spoken communications with individual participants, have also been adopted in several recent studies of high-risk outdoor sports (Arijs et al., 2017; Brymer, 2013; Brymer \& Mackenzie, 2017; Brymer \& Oades, 2009; Brymer \& Schweitzer, 2013a,b; 2017a,b; Feletti et al., 2017; Feletti \& Brymer, 2018; Hallandvik et al., 2017; Holmbom et al., 2017). These approaches were not used here. Somewhat confusingly, the term autoethnography, often with the prefix "creative" or "evocative" is also used in non-analytical autobiography, but with a very different meaning (Buckley, 2015). Again, that approach was not used here.

Participant observation, as used here, involves: observing other participants in action; interpreting their actions from the basis of one's own parallel experiences; tracking one's thoughts, feelings and actions, as they take place; deliberately taking specific actions so as to test their cognitive, affective, and physical outcomes; and analysing all these experiences 
essentially as a large-scale, highly-replicated set of tests with multiple independent and dependent variables.

The focus here is on the cognitive components in surfing, from a surfer's perspective. The author learned to surf at a much later age (over 40) than most surfers. This requires greater deliberation and conscious thought, than surfers who learned as children. It enables, and perhaps forces, one to pay careful attention to what one is doing, and why. This allows an experimental approach, which is distinct from the retrospective analysis of memories (Buckley, 2015, 2016a). Participant observation may involve conversations, but not formal ethnographic interviews. Such conversations may occur either in the surf itself, or on-shore, before or after surfing. In either case, there is no record of the precise phraseology used, only its general content or "headnotes" (Ottenberg, 1990). Therefore, these conversations do not yield verbatim quotes to illustrate findings.

The author has over 20 years' self-taught surf experience, locally and in surf destinations worldwide. Some travel, boards, and wetsuits were sponsored by surf tour operators and equipment manufacturers. Total time surfing, estimated from years, days per year, and hours per day, is at least $2000 \mathrm{hr}$. This represents around 500,000 individual waves observed, based on a typical 14-second wave period, and including close-range observations of surfers manoeuvring for and riding each wave. It also includes at least 5,000 waves ridden by the author, albeit inexpertly. The author is an Anglophone Caucasian male, currently 65 years old, with a lifetime background in intermediate-level adventure sports. His perspective may differ from those of surfers of different genders, ages, ethnicities, abilities and interests.

This observational data set represents large-scale replication of the manoeuvres discussed below. This replication is biased towards, though not restricted to, a particular subset of surfers, namely intermediate to expert short-board surfers in well-known, crowded surfing locations. This subset comprises the majority of surfers worldwide. Except incidentally, this study does not include bodyboards, longboards, softboards, surf-club rescue boards, stand-up paddleboards, foilboards, tow-in strapboards, or waveskis; or learners, professionals, or bigwave surfers. The author does also have experience on sailboards and kiteboards, but the cognitive skills required are different from surfing, and are not included here.

Collection and analysis of data for this research was approved by the Human Research Ethics Committee of the author's university under the provisions of its Research Ethics Manual, Vol. 17 ss. 4.6, 5.1 (Griffith University, 2018). It is compliant with the Australian National Statement on Ethical Conduct in Human Research (NHMRC, 2018) S 5.1.22 (a) and (b), and the principles propounded by Tolich (2010). It was conducted in public spaces, with no formal interviews, inducements, interventions or interferences, identification of any observed persons, or behaviour modifications, and all interpretation conducted by the author. Results are reported so that no individuals other than the author are identifiable by any mechanism, including name, role, image, geotag or other digital identifier, or place/time coordinates.

All results, as presented below, are derived from data and analytical procedures as outlined above. As for all participant observation, they necessarily represent the perspective and experiences of the author, derived from observations of many other participants. To maximise reliability, only the most robust and general results are presented, in simplified form. Results are presented in declarative format. A general caveat applies, not repeated in each case, that these results reflect the author's particular participant observation, experience, and perspectives. 
The focus is only on cognitive components of expertise: that is, components that require expert knowledge and involve focussed consideration. Most cognitive skills are independent of body position or movement, and allow time for reconsideration. One is aware that one is thinking, and what one is thinking about. Anything that happens too quickly for this, or is unavoidably linked to particular body positions or movements, has been considered as an autonomic physical skill. These are also controlled by the brain, but perhaps not in the same way (Yarrow et al., 2009). Under that definition, cognition in surfing extends from timescales of days, hours and minutes, down to seconds or less. Examples at each timescale are presented in the next sections.

Contrary to the conventional definition as above, however, I also argue here that for skilled surfers, cognitive processes can be identified even for very spatially-specific actions at subsecond timescales. These are timescales generally associated with so-called autonomous skills, not generally considered as cognitive. I argue here that whilst surfing does also involve complex cognitive processes at longer time-scales, it is these sub-second timescales that can provide the most fundamental insights into human psychology. The same applies for many other forms of outdoor recreation, not studied here.

\section{Results}

\subsection{Timescale days to minutes: choosing a break and paddling out.}

For local surfing (i.e., excluding surf travel), cognitive components start at a timescale of $\sim 1$ day. Surfers watch weather and swell conditions, to plan the next day's surf. On the morning of a surf day, surfers typically check conditions, either in person, using online resources such as surfcams, or by communicating with friends. They decide whether or not to surf that day, and if so, when, where, and with what board. Larger swells generally require longer boards.

Relevant conditions include: swell size, direction, shape, and period; tide amplitude and stage; nearshore currents; wind direction, strength, and forecast; and the shape of ocean floor bedforms such as sandbars, which determine how different waves will break at different tide stages. All of these change from day to day, and hour to hour. Surfers assess these factors relative to their own skills, energy levels, and risk aversion. For example, a rocky point break may have excellent waves, but access may require a precisely timed series of steps and jumps across slippery barnacle-covered rocks, with a risk of being washed violently onto those rocks if the timing is poor.

Once a location is chosen, the surfer then has to decide exactly where to paddle out. At some surf breaks under some conditions, there is only one realistic option. For example, some reef breaks have only one narrow channel. Often, however, there are choices. At a beach break, this means finding a promising rip current. At a point break, it means choosing the best rock to jump off. Such decision making in itself involves expert cognitive processing. One entry point may provide the least risk of injury but the greatest risk of being unable to paddle through the broken waves (the whitewash), especially if there are strong currents or "sweep". Another possible entry point may present a higher risk when jumping off, but a greater chance of successfully paddling through the whitewash. Particular breaks have their own idiosyncrasies. 
It needs skill and nerve to time a jump off a rock precisely so as to land on a wave reflecting back, and dive under the next wave before it smashes onto the rock. In other scenarios, surfers may elect to paddle out of a river mouth on an outgoing tide, despite shark risk, and thence paddle round a headland to the surfable wave. These are cognitive decisions that may have substantial consequences that the surfer needs to consider and reconsider carefully. The paddle-out itself includes continual cognitive processing, watching for risks, for opportunities to find rips, for incoming waves, for other surfers either riding waves or with loose boards, and so on. Once "out the back" of the zone where waves are breaking, the surfer can rest briefly, as long as the sweep (longshore current) is not strong. But that is only the beginning.

\subsection{Timescale minutes to seconds: positioning and wave selection.}

To catch a wave requires continuous complex cognitive processes and associated actions. One of these is choosing which waves to paddle for, but a surfer can rarely decide this on wave shape alone (Furley \& Dörr, 2016). That case occurs only under two circumstances. The first is when a surfer is surfing alone, either in a remote location, or at a "peak", a place where waves are breaking predictably. With more than ten million surfers worldwide, such solitude is unusual. The second is in one-on-one surf competitions using a priority buoy (Furley and Dörr, 2016), with non-competitors excluded from the site. This applies only to high-ranked competitions. Competitors in the global professional league comprise $\sim 0.002 \%$ of the world's surfers. Even for them, the one-on-one format only applies during formal competitive events, not practice, and this is estimated as $<5 \%$ of their total surf time.

In consequence, almost all surfing involves competition for waves. This requires cognitive skills, akin to a multi-factor, multi-player game. First, surfers "check the line-up". That is, they watch to see where waves are breaking, how regular or irregular they are, and where other surfers are waiting. Throughout the session, they watch every wave as it arrives, and every wave caught by other surfers. This provides information both on the shape of each wave as it breaks, and on the skills and behaviours of individual surfers. This is equivalent to studying a game and its players. Surfers will also use prior knowledge of the surf break. From this first check, each surfer selects a point to paddle to, to wait for their first wave. They may mark that point mentally, through water depth and landmarks onshore.

This is the first move of a strategy. Depending on their own skills, and how well-known they are to other surfers present, each surfer must decide where to sit in the line-up. At the head of the line-up are the most skilled surfers, who can catch the most difficult waves. Any surfer can paddle past them to the "inside", but unless that surfer is even more skilled, they will be ignored. Surfers who are older and slower, or intermediate in skill, like the author, must adopt a second-tier strategy. One can wait for larger "set" waves that break far out, or "wide". This, however, then requires manoeuvering around surfers "caught inside" by the breaking wave. At some sites, waves break consistently at different speeds in different sections, depending on wave size and direction, water depth, and ocean bedform. One can wait just outside a high-speed section. If another surfer catches the wave further "up the line" but does not get past the fast or "close-out" section, then one has an opportunity to take that wave. A close-out is a section of a wave that collapses into whitewash, rather than breaking smoothly from one end to the other. Of course, other surfers will have the same plan, creating localised congestion and competition.

In addition, each surfer often has to make a split-second decision whether or not to go, depending on whether they think surfers already riding will or will not "make the section": 
i.e., get through, round, or over the fast or breaking part of the wave. If skilled, they will be travelling fast. In surfing, it is a major social crime (and also physically dangerous) to "drop in" or take a wave in front of someone who is already riding it. Apart from potential collisions, blatant drop-ins can provoke verbal or physical retaliation. So one must be very confident that a surfer will not be able to make the section, before taking their wave oneself.

At a crowded break there may be a whole line of surfers, sitting almost knee to knee, all hoping for that same wave. Time and again, you may paddle for the next wave, confident that it "has your name on it", meaning that you will have right of way, only to find that someone else has taken that wave "on the inside", closer to the breaking section, and thus has gained right of way. Patience is critical, and strategy indispensable. In addition, everything is fluid and constantly changing. Every wave is different, and every surfer is constantly paddling around. The positioning strategy of any individual surfer must be equally flexible.

A "line-up" is a section of the ocean surface. At any section of the line-up, individual surfers can position themselves further offshore, or further inshore. As they see waves rolling in from the horizon, they can paddle up or down the line-up, and also offshore or inshore, to where they think they have the best chance of catching a wave. This is a continuous strategic process, and it involves letting most waves go by, in order to have the best chance at a few. This is wave selection, but it is not based only how high a score the wave could yield for a highly skilled surfer in competition (Furley \& Dorr, 2016). Each surfer will also consider how likely they are to catch each wave, not just physically, but in terms of right of way.

Surfers are not positioned evenly along the line-up. Commonly they are clumped at the best take-off spots. It is pointless to sit at the "outside" edge of a clump, especially if the clump includes known skilled surfers, because they will always get the waves. One must paddle to the inside, but not too far. Or one can sit at the outside of one clump, but paddle to the inside of the next clump, when a likely wave arrives. Where several surfers are waiting near each other in the line-up, their chances of being able to claim each incoming wave depend on their relative positions inshore or offshore. Generally, surfers sitting further offshore will miss smaller waves breaking inshore, but can catch larger waves breaking further offshore. Those sitting far inshore may get "caught inside" in the whitewash of larger waves.

In addition to positioning, there are various manoeuvres that each surfer can attempt, in order to gain right of way. To paddle around a surfer who is already paddling for a wave, so as to take the inside position, is known as snaking. If blatant, it is frowned upon, and the surfer who has been snaked may refuse to cede right of way by getting off the wave. Instead, they may block or "fade" the snaker, forcing them into the whitewash. Often, however, the situation is not clear cut. A surfer further offshore may paddle for a wave and be in a position to catch it; but just as they are about to get to their feet, a surfer slightly inshore may paddle deliberately into their path and take the wave just inside. If challenged, they can claim that the first surfer was not "up and riding" and therefore did not have right of way. Skilled surfers can also "sneak" a wave, by taking off "late", on the inside of a surfer who is already riding the wave, and then claiming to have right of way. It is because of situations such as these that professional surf competitions use a priority buoy. But there is no such buoy in free surfing. Instead, surfers must use cognitive strategy as well as physical skill.

Communications, both verbal and non-verbal, form part of these strategies. If two surfers are paddling for the same wave, the surfer on the inside is entitled to call out so as to claim right of way, and the surfer on the outside is then required to exit the wave. This also applies if 
both surfers are already on their feet. Sometimes, however, the outside surfer cannot get off the wave, either because it is too large and steep, or because other surfers are in the way. This can lead to altercations. In practice, verbal calls are rarely needed, because surfers watch each other's behaviour very closely.

If a surfer with right of way is paddling for a wave, those outside are expected to stay out of the way, and not to block the take-off or spoil the wave shape, for example by crushing the lip into a "snowball". These norms are equivalent to road rules and are needed for safety. At crowded breaks, however, some surfers ignore these norms. They may paddle decisively for a wave, relying on body language to deter other surfers who in fact have right of way. They may do this especially if they think the surfer on the inside is fearful or incompetent; or if they are frustrated at not having ridden a wave for an extended period.

At beach breaks, where the surf is breaking on a sandy seabed, some waves form peaks or "A-frames", where a single wave breaks both to the left and the right at the same time. If two surfers are both waiting at the peak, they can communicate by calling out "Right" or "Left" so as to indicate which way they intend to take the wave. Generally they will go in opposite directions so both get the wave. At some breaks, however, a surfer can take off "behind the peak". That is, the surfer can take off on the left-breaking shoulder, but ride the wave to the right, or vice versa. This leads to a non-verbal "faking" strategy, where a surfer on the left shoulder paddles to the right, which gives them priority over a surfer on the right shoulder also paddling to the right. Once that second surfer cedes priority and pulls back, the first surfer can then turn left, so as to ride the wave to the left.

In very crowded line-ups, some intermediate surfers use a "gang" strategy, where each sacrifices some opportunities in order to create others. They form a clump that blocks out an entire section of the line-up. Instead of the surfer on the inside of the clump taking the wave, under difficult conditions, the gang blocks non-member surfers. This allows the gang member on the outside of the clump to make an uninterrupted take-off under easy conditions. The gang members paddle around to take turns on the inside or outside. This is a short-term strategy, since once other surfers observe it, they can disrupt it by paddling into the middle of the gang's "territory", but it can be quite effective for a brief period.

All the discussion above assumes that everyone at a surf break is riding surfboards. At many breaks, however, a wide range of surfcraft may be present in the same break, and each craft handles differently. To avoid collisions, surfers need cognitive skills to predict how each craft will behave. At some surf breaks, there may be shortboards, longboards, mini-mals, bodyboards, surf-school softboards, surf-club paddleboards, stand-up paddleboards, hydrofoil boards, sailboards, kiteboards, sailing catamarans, waveskis, ocean racing surfskis, kayaks, outrigger canoes, surf boats, and/or jet skis, all at the same time.

In theory, each of these craft should follow the same surf priority rules. In practice, some of them (or their operators) ignore the rules, or are unable to turn, or to get off a wave once they are on it. As a surfer, you may have priority on a wave technically speaking, but this means little if much larger craft are in your way and unable to avoid you. In addition, on gently breaking waves, a longboarder can get to their feet further offshore than a shortboarder, allowing them to claim priority. All of this requires additional cognitive skills; and each of these considerations can be dissected more finely to minute levels of detail. 
Even once a surfer is paddling for a wave and intends to take it, so that they are about to "take the drop", there are still last-moment cognitive components. The most important is a quick look in all directions: inside (towards the breaking section), to check nobody is already on the wave; outside, to check the wave is within one's capabilities; and forward, to check no one is in the way. If any of these checks is unfavourable, the surfer can pull back at the last moment. If they leave the decision too late, however, they may go "over the falls", which means being flung forward and down by a breaking wave, often in an uncontrollable fall.

All these manoeuvres involve complex cognitive strategies, including: a good understanding of wave behaviour; accurate knowledge of one's own physical capabilities; and the ability to anticipate the actions of other surfers, as competitors or opponents. These positioning manoeuvres are carried out whilst paddling, lying on the surfboard. They take place slowly enough that they can be reconsidered repeatedly whilst in progress, and aborted if they are thwarted by another surfer. They operate at timescales of minutes or seconds, down to subsecond decisions immediately prior to take-off. We now turn to the take-off itself.

\subsection{Timescale seconds to subseconds: take-off, turns, ride, and exit}

When a surfer paddles for a wave and "takes the drop", they must jump to their feet cleanly and quickly at precisely the right moment, as the board is pushed or thrown forward by the moving water. Their feet must move directly to the correct places on the board, depending on the size, speed, and steepness of the wave, and the angle of take-off. The surfer's body weight must be balanced exactly as needed to initiate the first turn without stalling or nose-diving. Generally, all of these actions must take place without looking or thinking about them, because the gaze and concentration must be on the wave itself and other surfers. From that moment until exiting the wave (or wiping out), the surfer relies principally on high-speed physical coordination at timescales of tenths or hundredths of seconds, gained through practice. Even these, however, include some components involving conscious cognition, as outlined below.

Once up and riding, there is a continuing series of high-speed decisions. These are driven by the shape and speed of the wave, other surfers who may be in the way and must be avoided, and the intended end point of the ride. These decisions are made at speed as one rides the wave, with no time for reconsideration. They are driven directly by immediate perception and proprioception. They are linked directly to immediate movements, to turn the board or alter its speed. If any mistakes are made, they lead to an immediate wipe-out, i.e. an uncontrolled fall. They are at the borderline between conscious cognitive processes, and learned physical skills carried out without conscious attention. This is the aspect of surfing that can yield insights and information of relevance to human psychology more generally.

Depending on the wave and the skill of the surfer, there are several options to exit a wave. These include: "cutting out", by turning over the back; "pulling in" to a barrel or close-out section until it shuts down; "straightening out", by turning shorewards away from the wave, or "riding the close-out", by making a final turn or aerial move on the breaking whitewash section. The actual moves require physical skills, but the decision when and how to exit the wave is a high-speed cognitive judgement, with little opportunity for reconsideration.

Whilst riding a wave, skilled surfers can make a variety of turns and manoeuvres, both on the wave itself, and in the air above. These manoeuvres rely on speed, momentum, balance, and weight shifts, for initiation and completion. These are what surfers are judged on in 
competition. The reason that wave selection is critical in one-on-one competition (Furley and Dörr, 2016) is that wave size and shape determine how many moves the competitor can make, and how highly each will be scored by the judges.

Different waves have different shapes and speeds. Waves may break either steeply or gently. A gently breaking wave is described as "soft" or "fat". Fat waves are easier to catch and ride than steep waves, but less exciting. The breaking section of the wave may travel either slowly or quickly along the length of the wave, depending on ocean bedform, water depth, wave angle and other factors. A "slow" wave, in this sense, is easier to catch than a "fast" wave. Slow waves are often also fat, and fast waves are often also steep or hollow; but not necessarily. Larger waves also move faster over the seafloor than smaller ones. This reflects the movement of the entire waveform relative to the seafloor, as distinct from the movement of the breaking section along the waveform. The speed and precision needed to catch a wave depends on its size, steepness, speed of forward movement, and the speed and shape of the breaking section.

To take off onto a slow fat wave is straightforward. The surfer positions themselves at the peak, where the wave will first start to break, and then paddles in the direction that the whole wave is travelling over the seafloor. The surfer must position their weight at a particular point on the board between nose and tail, so that the wave will push the board forward. Too far back, and the board will not catch the wave at all. Too far forward, and it will nosedive. Once the board catches the wave, the surfer must jump to their feet, known as a "pop-up", as the board slides down the face of the wave. That slide gives the board momentum, and the surfer can use that momentum to make a large sweeping turn, the bottom turn, in the direction the wave is breaking. This is how one first learns to catch a "green" wave as it breaks.

A hollow, fast-breaking wave is very different. The timing is extremely precise. Often, the board must be angled diagonally to the direction the wave is travelling, but not overly so. Sometimes, the surfer must dig the rail, the edge of the board, into the wave even as they are taking the drop, so that momentum from the take-off is along the wave as well as down the face. This requires extreme focus and concentration, especially in larger waves, and can induce both fear and thrill (Buckley, 2016a). Some waves are extremely thick and powerful, making them especially dangerous. Some waves have "steps", sudden changes in steepness partway down the wave, and these are particularly difficult to negotiate.

The front of a breaking wave is known as the face, and the top edge is the lip. If the wave breaks very steeply, so that the lip throws outward away from the face before falling, it can form a hollow air-filled tube of fast-moving water. This is known currently as a keg or barrel, and historically as a pipe or tube. Riding inside the barrel requires particular skill, but generates a much sought-after thrill amongst surfers. It needs very precise control of the board. Some barrels stay "open" so that a skilled surfer can ride inside the barrel, under the lip but ahead of the broken "foamball", and then emerge at the end. Others "shut down" so that the surfer is caught in breaking whitewash. Some waves break gently at first and barrel up later; others break directly as a barrel.

On days when conditions are particularly good, with large fast barrels forming, the most expert surfers catch the best barrels, for three reasons. First, they have the cognitive skills to pick the barrels that will stay open rather than shutting down. Second, they have the physical skills to accelerate their board along the wave, inside the barrel, so as to match the speed of the breaking barrel. Finally, they have the high-speed coordination needed to take off 
directly into the barrel. This may involve an "air drop", where the surfer falls through the air, standing on their board, onto the lower part of the wave, as the lip plunges over their head. As soon as the tail of the board contacts the water after the air drop, the surfer must instantly make a sharp turn, inside the barrel itself, without losing speed. This is a high-order learned skill.

\subsection{Cognitive components and subjective time dilation}

Do these moves and manoeuvres, with sub-second timescales, involve conscious cognitive skills, or unconscious autonomic physical skills? Is this even a valid distinction? (Yarrow et al., 2009). Under theoretical frameworks used in outdoor sport and recreation, such as Fitts' Law (Fitts, 1954) and the Law of Practice (Evans et al., 2018), these moves are skilled physical actions. As they are learned through practice, they undergo a transition from fully cognitive, requiring deliberate thought and attention, to fully automatic, carried out as a learned physical skill without any deliberate attention. Brain operations during skilled movements are currently subject to intensive research, focussing on the neurology of the sensorimotor cortex (di Fronso et al., 2016; Cheng et al., 2017), and the microarchitecture of brain white matter connections (Kahn et al., 2017).

What can evidence from surfing add to these analyses? The first finding is that learning highspeed, high-skill, high-precision, specialist manoeuvres generates the perception of subjective time dilation or "slow time" (Arstila, 2012; Wittman, 2013; Buckley, 2014). When a participant first attempts these manoeuvres, they are unable to track how the manoeuvre unfolds. They try the manoeuvre and they may or may not carry it out successfully, but they cannot tell how or why. After practice, however, they become able to follow what is happening at much greater speed than previously. In the take-off onto a wave, for example, a practiced surfer finds that they have time to check foot and body position, and the angle of the board in all three dimensions, during the tenths of a second it takes for the board to slice down the wave. As they become more practiced, a take-off on an easy wave can be completed without paying any particular attention. A take-off on a difficult wave, however, still requires complete attention, focus and concentration.

The second finding of this study is that even during extreme concentration, one can be aware that one is focussing, and one can be aware what one is focussing on. For example, in a takeoff into a barrel or onto a steep hollow wave, one can be aware that whilst already on one's feet, one is still also using a hand on the outer rail of the board, allowing one to lean one's bodyweight inward towards the wave face, completely off the board itself, so as to angle the board sharply into the face. Does that high-speed and very spatially-specific awareness constitute cognition? Emotionless concentration during a crux manoeuvre has been reported previously for participants in a range of high-risk, high-skill outdoor adventure activities (Buckley, 2016a). Participants perceived fear before commencing a crux manoeuvre, emotionless concentration during the manoeuvre itself, and thrill after completing it successfully. Previous studies, however, focussed only on emotion, not cognition.

The third finding relates to the widely adopted distinction between "slow" and "fast" thought, in the sense used by Kahneman (2011). Clearly, some types of thought are indeed slow, involving careful and extended cogitation and reconsideration. Writing articles provides an example. Some types of brain operations, in contrast, are indeed fast, in the sense that they drive a physical action without any conscious attention or decision. A counterpunch in boxing provides an example. But is there a definite dividing line, separating two distinct types of 
thought? Evidence from surfing suggests that there is not. Instead, there is a variable continuum in the "speed of thought", which is modified by practice. This is a new finding.

\section{Discussion}

As with all participant observation, the results reported here, albeit with large-scale replication, are ultimately derived from one person's perceptions. What evidence is there to corroborate these findings? We can compare other adventure activities studied using similar methods, and extreme sports studied using different methods.

Other analyses using participant observation indicate that sailboarding and kiteboarding involve many of the same considerations as surfing, and an additional set related to wind (Buckley, 2018a). Whitewater kayaking involves a different but analogous set of considerations, centred around the difficulty of individual rapids and entire river sections, variation in river flow, and the skill of individual kayakers (Buckley, 2018b). Skiing and snowboarding involve a specialised set of cognitive skills relating to weather, route finding, avalanche risk, and terrain risk including cliffs, tree wells, and cornices (Hallandvik et al., 2017). Hang-gliding requires careful cognitive processing of information on atmospheric processes, at timescales from multi-day to sub-second. Diving needs careful calculation of depths and time, drift currents and ascent rates. Wildlife watching needs additional cognitive skills related to animal behaviour.

Recent studies of various adventurous and extreme outdoor sports have focussed largely on participants' experiences, rather than cognition per se (Brymer, 2013; Brymer \& Mackenzie, 2017; Brymer \& Oades, 2009; Brymer \& Schweitzer, 2013a,b, 2017a,b; Andrianopoulos \& Vogiatzis, 2017; Feletti et al., 2017; Holmbom et al., 2017; Immonen et al., 2017; Taylor \& Elias, 2017; Wheaton, 2017; Feletti \& Brymer, 2018). Brymer and Oades (2009) cited kayakers, sailboarders and mountaineers, whose lives were transformed by extreme sports. BASE jumpers and proximity wingsuit flyers interviewed by Brymer and Oades (2009), Brymer and Schweitzer (2017b), and Holmbom et al. (2017), cited by Buckley (2018b), said that: "fear is a constant companion"; "you're at this level of alertness that you're not in a normal life"; "your awareness ... expands enormously"; "we are all going to die .. it is how we live that matters." Although clearly, proximity flying requires high-level cognitive skills exercised at high speed, these phenomenological studies focussed on participant experience rather than cognition.

As with surfing and skydiving, in climbing and mountaineering one can also identify a range of cognitive skills exercised at different timescales, even though these cognitive skills themselves have not been the focus of previous studies (Willig, 2008). Participants identify and study their routes carefully in advance. They pay careful attention to weather conditions and forecasts. They select appropriate protective gear to carry on each climb, and plan its placement. They plan each section of the climb as a series of individual moves, including dynamic moves reliant on momentum. The moves themselves require physical fitness and skill. They operate at a very fine level of detail, including each individual toe and finger hold or grip, the order in which these are made, and the body position in moving from one hold to the next. For his solo ascent of El Capitan in Yosemite National Park, climber Alex Honnold said that he learned every single body move for the entire ascent, on previous roped climbs, before making the successful solo attempt (Varsahelyi and Chin, 2018). Corresponding cognitive components can be identified for a very wide range of sports and outdoor activities 
on land, air and water (Jamal et al., 2019), including those involving animals (Gombeski et al., 2017), motors, weapons, or competition with opponents (Denis et al., 2017).

\section{Management Implications \& Research Priorities}

\subsection{Management}

Management implications are wide-ranging but straightforward. Surfing itself is not a heavily managed activity. There are a few sites where access or activities are restricted or otherwise managed, but these are the minority, and often controversial (Buckley et al., 2017). Most surfing sites are open access, and it is up to individual surfers to judge whether or not they are competent to surf there safely, on any particular occasion. Generally, nobody will stop them trying to paddle out, if they decide to do so. It is only in organised surf schools and guided surf tours that expert instructors will assess the skills of their individual charges or clients, and determine where to take them, and how to manage their education and safety. In most cases, they already do this competently, and their practices need not change as a result of the current study.

From a training perspective, this study sets out the range of different types of knowledge and skill that a successful surfer must acquire. A surf school or instructor can impart all of this knowledge, but not all at once. It is useful, however, to remind learners that jumping to one's feet on the board, whilst the most conspicuous aspect of successfully learning to surf, is in fact only one of many skills that need to be acquired in parallel. This study also suggests that instructors can help their pupils learn faster, if they encourage them to pay close attention to their own actions, at the same time as taking those actions. This also helps to maintain enthusiasm, since it gives pupils a specific course of action to improve skills. These approaches apply not only to surfing, but to all high-speed, high-skill, learned physical activities, including commercial professions as well as sports (Naito \& Hirose, 2014).

\subsection{Research}

As a broad research goal, could we construct models or frameworks that incorporate all the skill sets identified here, and compare them across a range of adventurous outdoor nature sports? If so, could we extend that model to other skilled activities? A mix of physical and cognitive skills is needed for many modern human activities considered routine, such as driving a car; or for any activity that involves a time-determined physical professional skill, such as working as a surgeon, a firefighter, or a chef (Po, 2008). Future research could apply these particular findings from surfing psychology, across other aspects of human life.

At closer focus, surfing suggests a close interplay between skills considered as cognitive, and those considered as physical (Yarrow et al., 2009). Individuals with learned physical skills can perceive, analyse, and react to external environments, and their own physical movements, at much shorter timescales than individuals without those particular skills. Analysing these processes for adventurous outdoor nature sports can tell us more about how the human brain operates more generally. This is the most significant aspect of the current study, and the most fundamental direction for future research.

For most animal species, and for humans in our recent evolutionary past, almost every aspect of life and survival required speedy perception, cognitive processing, and physical action, so as to obtain food and evade predators. This evolutionary history has shaped our brains, but 
we can no longer study it directly across the whole population, only in particular subcultures. In most modern human societies, adventurous outdoor nature sports are perhaps the closest aspect of our lives, to that evolutionary past. The psychology of these sports, including surfing, thus gives us a unique window into human brain function. In addition, they are relatively easy to study, from both practical and ethical perspectives. They thus provide research opportunities not readily available through other means.

\section{Conclusions}

Participant observation approaches can be valuable in examining the fine line between cognitive processes and physical skills. Some actions require deliberate attention and decisions, whereas others are learned through practice, and can be carried out without deliberate attention. Between these, there are actions that involve attention, but not deliberation. How do these happen, and how do we learn them? As outlined above, adopting the perspective of a surfer allows a researcher to identify the components of surfing where: (a) cognition blurs into action; (b) subjective time dilation permits extreme focus and concentration even at sub-second time scales; and (c) practice in anticipation, "seeing ahead" improves ability. The evolution of brain-body interactions at these very short timescales is as yet poorly understood.

To date, different approaches have been taken in different research fields, and they remain unconnected. In sport and exercise science, the focus is on practice to improve performance. Coaching effective practice in different activities is itself a learned skill. How practice is reflected in brain processes, however, is outside the scope of that discipline. In neurology, as reviewed earlier, the focus has been on identifying parts of the brain, at successively finer spatial and temporal scales, that are activated during highly skilled actions, or change as a result of long-term skill improvements.

Such approaches confirm that concentration in the instants before a crux move, is critical to performing that move successfully. As yet, however, these neurological changes cannot be matched to identifiable psychological attributes of thought. What form of cognition takes place during those brief focussed moments, when a skilled action is already under way, but still requires attention for successful completion? As neurophysiological monitoring equipment becomes increasingly portable and weather-resistant, we may be able to link measurements and perceptions during these critical instants. Meanwhile, participant observation approaches provide insights not otherwise available, from activities and circumstances not otherwise testable.

\section{Acknowledgements}

Amongst many surfing friends and sponsors who contributed to my surfing experience, I should like to express particular thanks to the late Allan Byrne, shaper, of Byrning Spears surfboards on the Gold Coast, Australia; and to Mariana Surf Charters in the Maldives.

\section{References}

Allerdissen, M., Güldenpenning, I., Schack, T., \& Bläsing, B. (2017). Recognizing fencing attacks from auditory and visual information: A comparison between expert fencers and novices. Psychology of Sport and Exercise, 31, 123-130. 
Anderson, L. (2006). Analytic autoethnography. Journal of Contemporary Ethnography, 35, 373-395.

Anderson, L., \& Austin, M. (2012). Auto-ethnography in leisure studies. Leisure Studies, 31, 131-146.

Andrianopoulos, V., \& Vogiatzis, I. (2017). Windsurfing: the physiology of athletic performance and training. In Feletti, F. (ed.), Extreme Sports Medicine, 357-363. Springer Nature, Basel.

Araújo, D., Hristovski, R., Seifert, L., Carvalho, J., \& Davids, K. (2017). Ecological cognition: expert decision-making behaviour in sport. International Review of Sport and Exercise Psychology, doi: 10.1080/1750984X.2017.1349826

Arijs, C., Stiliani, C., Brymer, G. E., \& Carless, D. (2017). Leave your ego at the door: A narrative investigation into effective wingsuit flying. Frontiers in Psychology, 8, 1895.

Arstila, V. (2012). Time slows down during accidents. Frontiers in Psychology, 3, 196.

Bilalić, M. (2017). The Neuroscience of Expertise. Cambridge University Press.

Bradburn, N. M., Rips, L. J., \& Shevell, S. K. (1987). Answering autobiographical questions: The impact of memory and inference on surveys. Science, 236, 157-161.

Brown, R. \& Kulik, J. (1977). Flashbulb memories. Cognition, 5, 73-99.

Brymer, E. (2013). Risk and extreme sports: a phenomenological perspective. Annals of Leisure Research, 13, 218-39.

Brymer, E., \& Mackenzie, S. H. (2017). Psychology and the extreme sport experience. In F. Felletti (ed.), Extreme Sports Medicine, pp. 3-13. Springer, Berlin.

Brymer, E., \& Oades, L. (2009). Extreme sports: A positive transformation in courage and humility. Journal of Humanistic Psychology, 49, 114-126.

Brymer, E., \& Schweitzer, R. (2013a). Extreme sports are good for your health: A phenomenological understanding of fear and anxiety in extreme sport. Journal of Health Psychology, 18, 477-487.

Brymer, E., \& Schweitzer, R. (2013b). The search for freedom in extreme sports: a phenomenological exploration. Psychology of Sport and Exercise, 14, 865-873.

Brymer, E., \& Schweitzer, R. (2017a). Phenomenology and the Extreme Sport Experience. Taylor \& Francis, Abingdon.

Brymer, E., \& Schweitzer, R. D. (2017b). Evoking the ineffable: The phenomenology of extreme sports. Psychology of Consciousness: Theory, Research, and Practice, 4, 63-74.

Buckley, R.C. (2014). Slow time perception can be learned. Frontiers in Psychology, 5, 209. 
Buckley, R.C. (2015). Autoethnography helps analyse emotions. Frontiers in Psychology, 6, 209.

Buckley, R.C. (2016a). Qualitative analysis of emotions: fear and thrill. Frontiers in Psychology, 7, 1187.

Buckley, R.C. (2016b). Nature fix: addiction to outdoor activities. Journal of Behavioural Addiction, 5, 557-558.

Buckley, R.C. (2017). Analysing adventure: a leisure lifepsychle? Annals of Leisure Research, 21, 533-538.

Buckley, R.C. (2018a). Ageing adventure athletes assess achievements and alter aspirations to maintain self-esteem. Frontiers in Psychology, 9, 225.

Buckley, R.C. (2018b). Nature sports, health and ageing: the value of euphoria. Annals of Leisure Research, 21, 533-538.

Buckley, R.C. (2018c). Chronic pain and fatigue: timescale, feedback, and overrides. Pain, $159,1429-1430$.

Buckley, R.C. (2018d). To analyse thrill, define extreme sports. Frontiers in Psychology, 9, 1216.

Buckley, R.C., Guitart, D., \& Shakeela, A. (2017). Contested surf tourism resources in the Maldives. Annals of Tourism Research, 64, 185-199.

Cater, C., and Cloke, P. (2007). Bodies in action: the performativity of adventure tourism. Anthropology Today, 23, 13-16.

Chan, J. S., Wong, A. C., Liu, Y., Yu, J., \& Yan, J. H. (2011). Fencing expertise and physical fitness enhance action inhibition. Psychology of Sport and Exercise, 12, 509-514.

Chang, H. (2016). Autoethnography as Method. Routledge, London.

Chapman, D. W., Needham, K. J., Allison, G. T., Lay, B., \& Edwards, D. J. (2008). Effects of experience in a dynamic environment on postural control. British Journal of Sports Medicine, 42, 16-21.

Cheng, M. Y., Wang, K. P., Hung, C. L., Tu, Y. L., Huang, C. J., Koester, D., ... \& Hung, T. M. (2017). Higher power of sensorimotor rhythm is associated with better performance in skilled air-pistol shooters. Psychology of Sport and Exercise, 32, 47-53.

Chiu, C. N., Chen, C. Y., \& Muggleton, N. G. (2017). Sport, time pressure, and cognitive performance. Progress in Brain Research, 234, 85-99.

Denis, D., Rowe, R., Williams, A. M., \& Milne, E. (2017). The role of cortical sensorimotor oscillations in action anticipation. NeuroImage, 146, 1102-1114. 
Di Fronso, S., Robazza, C., Filho, E., Bortoli, L., Comani, S., \& Bertollo, M. (2016). Neural markers of performance states in an Olympic athlete: an EEG case study in air-pistol shooting. Journal of Sports Science and Medicine, 15, 214-222.

Draganski, B., Gaser, C., Busch, V., Schuierer, G., Bogdahn, U., \& May, A. (2004). Neuroplasticity: changes in grey matter induced by training. Nature, 427, 311-312.

Ericsson, K. A., Charness, N., Feltovich, P. J., \& Hoffman, R. R. (2006). The Cambridge Handbook of Expertise and Expert Performance. Cambridge, UK: Cambridge University Press.

Evans, N. J., Brown, S. D., Mewhort, D. J. K., \& Heathcote, A. (2018). Refining the Law of Practice. Psychological Review, 125, 592-605.

Feletti, F., Aliverti, A., Henjum, M., Tarabini, M., \& Brymer, E. (2017). Incidents and injuries in foot-launched flying extreme sports. Aerospace Medicine \& Human Performance, $88,1016-1023$.

Feletti, F., \& Brymer, E. (2018). Injury in kite buggying: the role of the 'out-of-buggy experience'. Journal of Orthopaedic Surgery Research, 13, 104.

Fitts, P.M. (1954). The information capacity of the human motor system in controlling the amplitude of movement. Journal of Experimental Psychology, 47, 381-391.

Flanagan, J. C. (1954) The critical incident technique. Psychological Bulletin, 51, 327-358.

Ford, N. J., and Brown, D. (2005). Surfing and Social Theory: Experience, Embodiment and Narrative of The Dream Glide. Routledge, London.

Ford, S. (2016). Integral Consciousness and Sport: Unifying Body, Mind, and Spirit Through Flow. Outskirts Press.

Furley, P., \& Dörr, J. (2016). “Eddie would(n't) go!” perceptual-cognitive expertise in surfing. Psychology of Sport and Exercise, 22, 66-71.

Gardner, R.S., Mainetti, M., \& Ascoli, G.A. (2015). Older adults report moderately more detailed autobiographical memories. Frontiers in Psychology, 6, 631.

Gombeski Jr, W. R., Camargo, F. C., Wiemers, H., Jehlik, C., Barger, P. H., \& Mead, J. (2017). Preventing horse-related injuries by watching out for other humans. Journal of Outdoor Recreation and Tourism, 19, 11-16.

Griffith University (2018). Griffith University Research Ethics Manual (46 vv). https://www.griffith.edu.au/research/research-services/research-ethics-integrity/human/gurem. Accessed 6 October 2018.

Hallandvik, L., Andresen, M. S., \& Aadland, E. (2017). Decision-making in avalanche terrain-How does assessment of terrain, reading of avalanche forecast and environmental observations differ by skiers' skill level? Journal of Outdoor Recreation and Tourism, 20, 45-51. 
Holmbom, M., Brymer, E., \& Schweitzer, R. D. (2017). Transformations through proximity flying: A phenomenological investigation. Frontiers in Psychology, 8, 1831.

Immonen, T., Brymer, E., Orth, D., Davids, K., Feletti, F., Liukkonen, J., \& Jaakkola, T. (2017). Understanding action and adventure sports participation: an ecological dynamics perspective. Sports Medicine - Open, 3, 18.

Jamal, S. A., Aminudin, N., \& Kausar, D. R. (2019). Family adventure tourism motives and decision-making: A case of whitewater rafting. Journal of Outdoor Recreation and Tourism, $25,10-15$.

Jones, S.H., Adams, T.E., \& Ellis, C. (Eds.). (2016). Handbook of Autoethnography. Routledge, London.

Kahn, A. E., Mattar, M. G., Vettel, J. M., Wymbs, N. F., Grafton, S. T., \& Bassett, D. S. (2017). Structural pathways supporting swift acquisition of new visuomotor skills. Cerebral Cortex, 27, 173-184.

Kahneman, D. (2011). Thinking, Fast and Slow. Farrar, Straus \& Giroux, New York.

Karlinsky, A., Zentgraf, K., \& Hodges, N. J. (2017). Action-skilled observation: issues for the study of sport expertise and the brain. Progress in Brain Research, 234, 263-289.

Kraeutner, S. N., McWhinney, S. R., Solomon, J. P., Dithurbide, L., \& Boe, S. G. (2018). Experience modulates motor imagery-based brain activity. European Journal of Neuroscience, 47, 1221-1229.

Loffing, F., \& Cañal-Bruland, R. (2017). Anticipation in sport. Current Opinion in Psychology, 16, 6-11.

Loftus, E.F. (2017). Eavesdropping on memory. Annual Review of Psychology, 68, 1-18.

Mallek, M., Benguigui, N., Dicks, M., \& Thouvarecq, R. (2017). Sport expertise in perception-action coupling revealed in a visuomotor tracking task. European Journal of Sport Science, 17, 1270-1278.

Mann, D. T., Williams, A. M., Ward, P., \& Janelle, C. M. (2007). Perceptual-cognitive expertise in sport: a meta-analysis. Journal of Sport and Exercise Psychology, 29, 457-478.

Martin, S. A., and Assenov, I. (2012). The genesis of a new body of sport tourism literature: A systematic review of surf tourism research (1997-2011). Journal of Sport \& Tourism, 17, 257-287.

Merleau-Ponty, M., 1945. Phénoménologie de la Perception. Éditions Gallimard, Paris. 696 pp.

Mendez-Villanueva, A., \& Bishop, D. (2005). Physiological aspects of surfboard riding performance. Sports Medicine, 35, 55-70. 
Mendez-Villanueva, A., Perez-Landaluce, J., Bishop, D., Fernandez-Garcia, B., Ortolano, R., Leibar, X., et al. (2005). Upper body aerobic fitness comparison between two groups of competitive surfboard riders. Journal of Science and Medicine in Sport, 8, 43-51.

Montero, B. G. (2016). Thought in Action: Expertise and the Conscious Mind. Oxford University Press.

Morin, A., Runyan, J. D., \& Brinthaupt, T. M. (2015). Editorial: inner experiences: theory. Measurement, frequency, content, and functions. Frontiers in Psychology, 6, 1758.

Naito, E., \& Hirose, S. (2014). Efficient foot control by Neymar's brain. Frontiers in Human Neuroscience, 8, 594.

Nathanson, A., Haynes, P., \& Galanis, D. (2002). Surfing injuries. American Journal of Emergency Medicine, 20, 155-160.

National Health and Medical Research Council, Australia (2018). National Statement on Ethical Conduct in Human Research. https://nhmrc.gov.au/about-us/publications/nationalstatement-ethical-conduct-human-research-2007-updated-2018 Accessed 6 October 2018.

Ottenberg, S. (1990). Thirty years of fieldnotes: changing relationships to the text. In Sanjay, R. (ed.), Fieldnotes: The Makings of Anthopology (pp. 136-160). Cornell University Press.

Pace, S. (2016). Contested concepts: negotiating debates about qualitative research methods such as grounded theory and autoethnography. In Constructing Methodology for Qualitative Research (pp. 187-200). Palgrave Macmillan, UK.

Po, P. (2008). https://m.youtube.com/watch?v=yPf6VKJ5cKw. Dreamworks Animation, Glendale CA.

Portugal, A.C., Campos, F., Martins, F., \& Melo, R. (2017). Understanding the relation between serious surfing, surfing profile, surf travel behaviour and destination attributes preferences. European Journal of Tourism Research, 16, 57-73.

Smith, D. M. (2016). Neurophysiology of action anticipation in athletes: A systematic review. Neuroscience \& Biobehavioral Reviews, 60, 115-120.

Spradley, J. (1980). Participant Observation. Holt, Rinehart \& Winston, New York.

Stahlke Wall, S. (2016). Toward a moderate autoethnography. International Journal of Qualitative Methods, 15, 1-9.

Taylor, K.S., \& Elia, E.A. (2017). Surfing and skimboarding medicine. In Feletti, F. (ed.), Extreme Sports Medicine, 245-255. Springer, Chamonix.

Telesford, Q. K., Ashourvan, A., Wymbs, N. F., Grafton, S. T., Vettel, J. M., \& Bassett, D. S. (2017). Cohesive network reconfiguration accompanies extended training. Human Brain Mapping, 38, 4744-4759. 
Tolich, M. (2010). A critique of current practice: Ten foundational guidelines for autoethnographers. Qualitative Health Research, 20, 1599-1610.

Toner, J., \& Moran, A. P. (2017). A Critical Introduction to Sport Psychology. Routledge.

Varsahelyi, E.C., and Chin, J. (2018). Free Solo. National Geographic, Washington DC.

Wheaton, B. (2017). Surfing through the life-course: silver surfers' negotiation of ageing. Annals of Leisure Research, 20, 96-116.

Willig, C. (2008). A phenomenological investigation of the experience of taking part in 'extreme sports'. Journal of Health Psychology, 13, 690-702.

Winkler, I. (2018). Doing autoethnography: facing challenges, taking choices, accepting responsibilities. Qualitative Inquiry, 24, 236-247.

Wittmann, M. (2011). Moments in time. Frontiers in Integrative Neuroscience, 5, 66.

Wittmann, M. (2013). The inner sense of time: how the brain creates a representation of duration. Nature Reviews Neuroscience, 14, 217-223.

Yarrow, K., Brown, P., \& Krakauer, J. W. (2009). Inside the brain of an elite athlete: the neural processes that support high achievement in sports. Nature Reviews Neuroscience, 10, 585-596. 